\title{
Biomedical and Social Sciences Grey Literature
}

This appendix provides a compilation of examples of grey literature from biomedical and social science disciplines. The resources provided here are only a selection of resources. Some of these resources have been referred to throughout this book and are presented here for easy access. There is no single resource for locating all biomedical and social sciences grey literature.

There is an ongoing debate as to what constitutes grey literature. Grey literature can include government publications, policy and management data, and statistical reports from organizations such as the World Health Organization (WHO).

AcademyHealth

- www.academyhealth.org/index.cfm

- Links to websites and journals about advancing research toward policy and practice

American Association of Retired Persons (AARP) Public Policy Institute

- www.aarp.org/research/ppi

- Part of AARP's nonprofit and nonpartisan organization

- Information on health issues and policies of importance to adults older than 50 years of age in the United States

European Medicines Agency

- www.ema.europa.eu/ema

- Evaluation of pharmaceuticals for potential use in the European Union

Kaiser Family Foundation

- kff.org

- Health policy information and analysis of issues related to healthcare

Kaiser Permanente Institute for Health Policy

- www.kpihp.org

- Highlights and analyses of significant national health policy issues and customized policy reports for a variety of audiences 


\section{Appendix C}

\section{MedlinePlus}

- www.nlm.nih.gov/medlineplus

- Consumer health information resource from the National Library of Medicine and the National Institutes of Health

- Locate healthcare organizations and societies publishing reports on specific health topics

National Center for Complementary and Alternative Medicine (NCCAM)

- nccih.nih.gov/research/results

- Part of the National Institutes of Health

- NCCAM supports rigorous research on complementary and alternative medicine (CAM), trains researchers in CAM, and disseminates information to the public

\section{OAIster}

- https://oaister.worldcat.org

- Worldwide open access resources available from Worldcat.org for free

- Contains grey literature in various formats such as books, statistics datasets, theses, and video/audio files

\section{OpenGrey}

- www.opengrey.eu

- Bibliographical references of grey literature produced in Europe covering science, technology, biomedical science, economics, social science, and humanities

- Technical reports, doctoral dissertations, conference papers, official publications, and other types of grey literature

\section{Partners in Information Access for the Public Health Workforce}

- https://www.phpartners.org/ph_public

- Collaboration of U.S. government agencies, public health organizations, and health sciences libraries; includes public health literature

Research and Development (RAND) Corporation

- www.rand.org

- Nonprofit and a nonpartisan institution that started in the 1940s

- Contains reports and reviews of public policy that can influence health, and social and economic policies

Virtual Health Library

- regional.bvsalud.org/php/index.php 
- Allows searching of LILACS, the Latin American and Caribbean Health Science Literature database, and other portals that may contain grey literature; available in English, Portuguese, and Spanish

\section{WorldCat}

- www.worldcat.org

- Information of holdings of many libraries worldwide

- Use WorldCat's advanced search feature to search for the term grey literature and once results appear, use the bar on the left with the heading Formats to limit the search results to "Internet Resource" to see a list of entries on grey literature.

\section{WHO}

- www.who.int/about/en

- Contains information on health statistics, health topics, and health policies 